\title{
The Studying The Effect Of Social Capital On Job Satisfaction in General Inspection Organization of Iran (GIO)
}

\author{
Darvish Hasan ${ }^{1}$, Jandaghi Gholamreza ${ }^{2, *}$, Mashayekhi Maryam ${ }^{1}$ \\ ${ }^{1}$ Management Department, Payam Noor University, Tehran, Iran \\ ${ }^{2}$ Faculty of Management and Accounting, Farabi Campus, University of Tehran, Iran \\ *E-mail address: jandaghi@ut.ac.ir
}

\begin{abstract}
In this research has been paid to the research and study of new concepts in management that is considered to the attention of many researchers in various fields including economics, social sciences, and political science and ... because of its strand nature. This study investigates the effect of social capital on job satisfaction of managers and employees in the State General Inspection Organization. The purpose of this study, the type of application and data collection methods, descriptive. This study is called correlation research because of the relationship between two or more variables. In this study has been investigated the model by using exploratory and confirmatory analysis statistics. The statistics society of this research is managers, experts and employees of the State General Inspection Organization. Confirmatory factor analysis of social capital in the first question of all questions except 58 and $61 \mathrm{t}$-value are acceptable to that question will be removed and the job satisfaction of first-order factor analysis of questions 2 and 31 are removed and values $\mathrm{x}^{2} / \mathrm{df}$ First-and second-order confirmatory factor analysis, and RMSEA of social capital and job satisfaction of first-and second-order model is indicative of the suitability and the value of $\mathrm{x}^{2} / \mathrm{df}$ and RMSEA T-value of the structural model and the necessary modifications are appropriate.
\end{abstract}

Keywords: social capital; job satisfaction; the State General Inspection Organization; Iran

\section{INTRODUCTION}

Social capital is a way of giving meaning to the term non-tangible resources, community resources, such as trust and shared values that are based on the consistency of their daily life. Social capital as they create relationships with people in the 1990s was an important concept, and was interested in the social sciences. With the favorable field of social issues in the field of organization and management of the past have, in the area of social capital and its use in organizational studies has increased rapidly. According to the organization's social capital in recent years, the importance of knowledge-based organizations and network growth has been considered. Social capital, according to its nature, can have advantages and disadvantages for the organization, Development of social capital requires an understanding of the relative costs 
and benefits, Given that the managers interested in investing in this area is necessary (Faghihi, Feizi, 2007, 23).

In today's society where people spend a considerable part of their daily activities earn, or preparing himself for job activites by various educations, Comprehensive discussion of the nature of employment and found it important, Because they may lack the necessary skills, interest, or are dissatisfied with their jobs. But part of the motivation and productivity on the job of coordination between job characteristics and abilities, needs, interests and values depend on the people. This person will coordinate the job satisfaction and dissatisfaction with the lack of it. Satifaction and dissatisfaction of job is connected to general life and can cause a person's life better, easier or not. So for this reason the pay more attention to job and related factors such as job satisfaction. And while everyone is trying to choose a job, In addition to satisfies the psychological needs and the material (Abbaszadegan, 2003, 195-197).

In today's society where people spend a considerable part of their daily activities or earn through their various training activities, occupational preparing for discussion of all aspects of employment and the nature of it has become important because They may lack the necessary skills, interest, or are dissatisfied with their jobs. But part of the motivation and productivity on the job depend on the coordinating the occupational characteristics with abilities, Need interests and values of people. This coordination will lead to job satisfaction or dissatisfaction and the lack thereof. Job satisfaction and dissatisfaction are related with life in general, and can cause a person to live better and be easier or not. For this reasons pay more attention to the job and related factors, such as job satisfaction, and while everyone is trying to choose a job that also satisfy the material needs of his mental as well (Abbaszadegan, 2003, 195-197).

\section{LITERATURE REVIEW AND HYPOTHESES}

\section{1. Social Capital and Its Dimensions}

Many are known the Pierre Bourdieu, James koleman and Robert Putnam as the classical theorists of social capital (Field, 2003). According to studies of social capital, the main differences between Putnam, Coleman and Bourdieu on social capital as defined shapes, is communication, or content (Carpiano, 2006), some researchers believe that Putnam's social capital as trust in social networking and introducing people to make Because, while Bourdieu's emphasis on social networks, social capital refers to natural resources (Carpiano, 2006). Faist (2000) known the social capital as the relationship between individuals and groups that define working relationships (formal and real transactions), the reaction between (mutual trust between the players) and the correlation between (symbolic relationship between individuals). (Pare \& V. Menzies, 2008, p. 54)

Dayton Johnson (2003) defined the social capital as follow: a social capital is an individual sacrifice and effort to promote partnerships with others. (Robert Oxoby, 2009, p1136) The other definition of social capital include: the use of external relations in a social structure that allows them to understand and use the opportunities and closed relationships with their cooperation. (J. Ferri, \& Deakins \& hittam, 2009, p141) Social capital affects employees in the course of their career advancement. Social capital facilitates the exchange of resources between units, product innovation and organizational learning and reinforcement, as well as the possibility of combining intellectual capital, social capital and increases the effectiveness of cross-departmental teams and the social capital and relationships with suppliers strengthens regional production networks. (Moshabaki, Ghlich Lee, 2008, p. 239)

Finally, according to research, the social capital can be: 
- Affect professional success.

- To help process seeking of employees and to establish better portfolio of employees in organization.

- Facilitate the exchange of resources between units.

- Innovation in the creation of intellectual capital and to stimulate multi-functional teams.

- Reduce job rotation of employees.

- Reinforce the relationship with suppliers, regional production network and interorganization learning. (Gholipour, Madhoshi and Jafarian; 2009, p. 115)

\section{2. Components of Social Capital}

\section{2. 1. Trust Network}

Trust can be defined to ensure the reliability of others and is divided into three components (Daskalakis \& Kauffeld-Mons, 2007). First a private trust that is a person to person. Second, is a people trust to the other people in a community, third the trust to organizations such as police, government, church, banks, etc...? These studies emphasis to the total trust and organizational trust. These two trusts back to social levels, while private trust is back to individual level (Kanck \& Keefer, 1997).

\section{2. 2. Shared Norms}

According to Putnam (1995) Social capital pointed to the collective norms and tendencies that come from social networks. (Goyal and Akhilesh, 2007) Common social norms are the sharing of people values and customs. (Oorschot \& Finsveen, 2010, p. 183). Norms are seen as social contacts and unwritten rules. For example norm for helping others, are good citizenship, cooperation and subordination to its interests in the community. (Dakhli \& de Clercq, 2004). Norms have strong relationship with trust. Individual norms play an important role in companies. This norms shape the trust between individuals (Annel Kaasa, 2009, p. 221).

\section{2. 3. Sympathy, Understanding and Mutual Respect}

The issue of sympathy in social asset can be related to moral issues based on the studies performed by Vayoyan. Besides, such sympathy can lead to wonderful moments in life. As the sympathy rate is high, people may not use the knowledge on immoral purposes (Alvani, Rabeei, 2004).

\section{2. 4. Social Cooperation}

There is a statement in the introductory part of the resolution of Islamic republic of Iran on social cooperation and democracy. It says the government is mainly aimed at developing the human being towards divine system in order to pave the way for talents to be thoroughly grown up. Such an aim can be only achieved as all social elements are thoroughly involved in developing their own society as best.

As mentioned earlier, the resolution can pave the way for such cooperation-based trends to be developed in all decision-making processes and provide the human being with best chances to be applied towards evolution-based purposes. In such conditions, everybody is responsible for their own growth and promotion (Mohammadi, 2010). 


\section{2. 5. Mutual Cooperation}

The studies performed on human histories best show their innate trend towards mutual cooperation to meet their own needs and afford a safe life. Such cooperation provides great educational approaches in the society. In order for such mutual cooperation being thoroughly embedded in social structures, the cooperatives working based on such principles will be the best source. As the goal is mainly built on developing the cooperation culture, we are essentially required to think about the approaches which consider the thought and movement as a value in national culture. Having involved the society in national cooperation means to make people face with a sort of change. To develop such a great change, it is essentially required to apply helpful approaches related to growing up and strengthening the culture. Such trends will be best welcomed by people in society as they have some advantages on social and economical grounds (Abbasi, 2009)

\section{2. 6. Collective Solidarity}

This word was first introduced by Richard G. Wilkinson to make a relationship between unequal income and the safety of a society. In fact, he applied such concept exchanging with social asset in which there is no vivid difference between them. Kawach considers the social asset as synonymous with social solidarity but the social asset concept includes an aspect of social solidarity (Kawach and Kennedy, 1997). So, Kawach considers the social solidarity being as an attitude of social asset (Kawach, 2006). Besides, the social solidarity provides the groups with opportunities to have strong relationships in local and world levels (Smith, 2009).

\section{2. 7. Collective Identity}

Identity is a process in which people strongly feel they are members of a single group. Kramer \& et al found out such feelings may lead to increased concerns on processes and collective results. In such conditions, there will be more chances for information to be exchanged. Lewicki \& Bunker best found out in their studies that such a wonderful collective identity not only increase the chances for changing the information but also may lead to increased cooperation among the members. As the members are of different identities, there may be some blocks on sharing the information, learning and knowledge management (Lewicki and bunker, 1996).

The collective identity prevents the social relationships from being personal. The family concept includes local government, race and occupation (Mohammadi, 2006, 137).

\section{3. Job Satisfaction}

Job satisfaction means a positive feeling towards a job resulting from the evolutions on person's performances (Chirwa, et al 2009, p. 15). It is considered being as an attitude of person's trends on his/her job and the positive relationship with employees' safety and performances (Spector, 1997). Besides, job satisfaction is different in international comparisons due to organizational culture (Leary \& Warton \& Quinlan, 2003, p. 223).

Considering the above-mentioned materials, job satisfaction refers to a sort of happy and satisfactory feeling a person may have on his own job. It is considered being as an emotional and positive feeling deriving from job evaluation. It is a concept with different aspects which have to be thoroughly considered. The employee's features, the kind of work, working environment and human relationships are some factors related to it (woodman \& Hellriegel, 1996). 


\section{3. 1. Factors Impacting on job Satisfaction in Spector's perspective}

\section{3. 1. 1. Frieng Benefits}

The resource manager is responsible for providing entertaining services, sport facilities, quality enhancement and working conditions and providing support on buying houses. He is essentially required to try to develop such services as best. Such entertaining plans may provide great opportunities to be applied to reduce the hardiness of job, make friendly relationship among the employees and family members. Services related to employees' entertaining programs may include extra hour activities in which the organization and employees may jointly benefit. So, it is essentially required to best follow the joint and mutual responsibility principles to achieve the mentioned goal. Therefore, any planning and supervising the programs related to such services should be performed by joint cooperation of employees (Mirsepasi, 2009, 339, 338).

\section{3. 1. 2. Promotion}

By promotion, it is meant promoting to a higher position in a job. Besides, the salary will increase as the employee promotes to a higher position. Human force provision through promotion from within is considered being as a policy for filling empty positions. Such an act will make the employees as most motivated to step towards progress in their own job. That is to mention, the employees may become disappointed if they fail to achieve their own goals while promoting to a higher position (Javadin, 1375, 174).

\subsection{3. Pay}

Employees most like their payment system and promotion policies to be as most fair and clear. Considering the kind of job and the employee's skill level, job satisfaction will be achieved as the salaries and benefits are fair. Some people warmly accept to get lower salary but work in a place they most like to. Some people like to have lower working hours. That is to mention, the salary cannot be as the best way to match the salary rate with job satisfaction. In fact, it requires what a person may think of justice and fairness in the organization. That is why the employees want their organization to treat based on fairness and justice. The promotionbased policies of an organization may provide the employees with better opportunities to grow up, accept more responsibilities and achieve a higher social position. So, such employees may have more job satisfaction (L.A. Witt and L.G. Nye, 1992, pp. 910-917).

\subsection{4. Communications}

As Treze said, an organization can meet the job satisfaction as the following are thoroughly considered:

1- Working days are full of communication-based opportunities

2- People best understand the need to make strong relationships with their colleges and clients

3- The employees have chances to communicate with different people

4- The working environment is planned in a way the communication is best encouraged

5- The employees don't feel they are far away their surrounding world

6- The communication with clients isn't considered being only as a job necessity

7- The social communication is considered being as a factor to reduce the efficiency 
Treze recommends the organizations to create a community space in which people can communicate together on working and organizational affairs. Such space shouldn't be considered as a place to rest but as a place the employees use their community thought powers to settle down the recent and upcoming problems in the organization. Such space may provide the employees with opportunities to know each other better and increase the cooperation and communication among them (Horman, 2003, 107).

\subsection{5. Coworkers}

Social needs are considered being as the human's main and basic ones. They most like to have friendly relationship with their colleges and be welcomed by their group members. So, the organizations are essentially required to provide conditions to meet such needs as best. Developing working groups with cooperation of people with same behaviors is most helpful in this area. It may lead to increased working motivation. In such conditions, people best support each other to settle down the problems. So, the organizational efficiency will be hereby increased (Zareei Matin, 2010, p. 220).

\subsection{6. Supervision}

This aspect reflects a sort of satisfaction a person may achieve as he directly communicates with the supervisor. Job satisfaction is best achieved through such direct relationship with the supervisor. The job satisfaction resulting from such relationship may relate to the supervisor's behaviors in two aspects:

1- Interpersonal support which refers to the supervisor's interest in providing the employees with welfare

2- Technical support which refers to the technical supports the supervisor provides for the employees as they need (Rawlinson \& et al, 1998).

\section{3. 1. 7. Operating Conditions}

Working environment is of crucial role in view of working facilities. The researches best show the employees prefer to work in a place with no dangers. So, the rate of noise and other environmental factors shouldn't be as most high or low. Besides, most employees prefer to work in a place near to their own house (Robins, 2009, 298).

\section{3. 1. 8. Nature of Work}

People most prefer jobs or positions to which they can use their skills and talents based on the opportunities available. In such condition, they can freely express their achievements. Such a job-based feature is called thoughtful challenge. Those tasks without the mentioned feature are boring. Besides, as the job challenges are extremely high, the worker or employee may be exhausted or feel disappointed. As the working challenges are moderate, the job will be more pleasing. (Katzell,thompson \& Guzo, 1992, pp. 195-211)

\section{3. 1. 9. Contingent Rewards}

Due and expedient rewards given to the employees based on exact evaluations can lead to improved performance and job satisfaction. Besides, they will result in employees' increased commitment to the organization and reduce the changing positions as best. As the employees think the rewards given to them aren't due to the burden of the tasks they are doing, they may stop working or don't do their best to accomplish the job (Visi, Savadi, 2007, 94). 


\section{4. The Relationship Between Social Asset and job Satisfaction}

The social asset is considered being as network of communications which make the access to the resources as most possible (Flamholtz, Bullen and Hua, 2002). Such asset is best recognized in the relationship between the people and positive job-based consequences. So, people with higher human assets most like to have influential friends in the organization in order to achieve new opportunities. In view of social asset, success is mainly dependent on the employees' social position rather than their own features. So, it the position of a person in social communication network which defines his/her social asset and may lead to differences in jobbased results (Ballaut, 2007). Those employees with higher social assets are in central social network. They may obtain some benefits through negotiating with top managers or their employers. Besides, they may get some more job opportunities in other organizations and enjoy their life as best (Arthur, Khapova and Wilderom, 2005). Elton Mayo strongly believes the efficiency of an organization can be increased through studying the human factors in industrial organizations. Besides, it is essentially required to meet the employee's personal needs in the organization to best increase the working efficiency. He strongly emphasizes on factors such as human motivation in inferior employees, respect to the employee and democratic management. Based on the studies performed, he to this conclusion that social and mental factors are of more crucial roles than material ones in increasing the efficiency. Considering the mentioned concept, the organization will be more efficient as the employees get socially satisfied. Mutual respect as an aspect of social asset can be potentially helpful in developing the communications, job satisfaction and creating a friendly atmosphere. This is strongly emphasized in Islamic culture (Zareei, Matin, 2010, 272).Human communications seem to be more helpful than other factors in increasing the job satisfaction. People most prefer to work with those they like to. They try their best to do the tasks for a good manager. They will stop working as they don't like the manager. They may cooperate with employees they are in good communication with. So, cooperation is achieved as a result of job satisfaction and pleasing working environment (Abbas Zadegan, 2003, 212).

In spite of the fact cooperation is another aspect of social asset, it makes the motivation factor as most strong because the employees think they are mainly involved in organizational tasks. In such condition, respect to self, job satisfaction and cooperation with management can be best improved. Cooperation is of crucial role in improving the group behaviors but it is hard to be applied. If applied correctly, it will have different consequences such as reduced nervous pressure in doing the tasks given, developed commitment to the goals assigned and accepting the changes. The employees will no longer stop working because they think they have a good place and atmosphere to work in. so, the cooperation will be strongly developed among the employees in such conditions (Abbaszadegan, 2003, 213).

\section{RESEARCH METHODOLOGY}

Since we are looking for improvement and optimization, as well as understanding the current conditions and helping the decision making process through this research project, the study at hand is an applied one regarding its objective, and a correlational research respecting its data collection method. The correlation is positive, which is gained through survey, and specifically is based on the Structural Equation Modeling (SEM).

SEM is a comprehensive statistical approach in the examination of the hypotheses concerning the relations between "the observed" and "the latent parameters". The acceptability of the hypothetical models in certain populations could be tested through this approach. If some 
parameters in managerial studies are currently latent, the necessity of using such models will increase day by day (Sarmad et al, 2002).

The main objective of this research project has been to examine the effect of the social assets on the job satisfaction of the General Inspection Organization (GIO) employees. The social assets result in advantages for people, including:

1. Establishment of cooperation among neighbors who can facilitate the social activity.

2. Promotion of safe behaviors within the norm boundaries, and increasing the social control

3. Affecting the physiologic approaches which increase the feeling of hope and the health care control.

4. Improving the individual access to the resources of the social networks, and

5. Increasing the understanding among the citizens of a country which includes the group solidarity or an ethical context.

\section{1. Research Objectives}

The main purpose of this research is studying the effect of social capital on job satisfaction of employees in the State General Inspection Organization. So identify the various dimensions of social capital and effective indexes on job satisfaction are any other purpose of this research. Also improve job satisfaction of employees in the State General Inspection Organization by increasing social capital of staffs, and finally, the conclusion of a conceptual model of how social capital effects on job satisfaction of employees in the organization will be provided.

Since the research is mainly concerned on improving the above-mentioned factors and better recognizing the current conditions to support the decision-making process, it is of applied one in view of goal. It is of correlation one in view of data collection. The correlation is negative and is performed through survey. Besides, it is based on structural equation modeling (SEM). The structural equation modeling is a comprehensive statistical approach applied to test the hypotheses on the relationships between the observed variables and unobserved ones. Through the mentioned approach it can be verified whether the theoretical models are accepted or not (Sarmad and et al, 2003).

\section{2. The Hypothesis}

There is a positive relationship between social capital and job satisfaction.

1 - There is a significant relationship between job satisfaction and trust.

2 - There is a significant relationship between job satisfaction and shared norms.

3 - There is a significant relationship between job satisfaction and cooperation and social solidarity 
4 - There is a significant relationship between job satisfaction and the empathy, understanding and mutual respect

5 - There is a significant relationship between job satisfaction and participation.

6 - There is a significant relationship between job satisfaction and collective identity

\section{3. Measurement}

Questionnaire is the tool applied to gather the data required. Following the theoretical studies and research background, different social asset dimensions and job satisfaction factors are extracted. Then the relationship between these two factors is being studied. Factor validity is a form of component validity which is obtained through factor analysis. Technical factor analysis is a statistics with high frequency in human science. Following the mentioned studies, the questionnaires were distributed among the employees working in the organization. Then the data collected were put upon deep analysis.

\section{4. Statistical population}

All managers and experts in supervision organization took part in current research as participants. Sampling method is of classification one. In order to assess the cohesion of the questionnaires, a number of 35 questionnaires were distributed and collected. Then the correlation coefficient for dependent and independent variables was estimated to be $0 / 84$. Then a number of 250 questionnaires were distributed. Out of which, a number of 139 ones were collected due to the fact some experts were absent.

\section{ANALYSIS AND PRESENTATION OF FINDINGS}

\section{1. Statistical Discriptions of Sample}

The statistical picture of the sample in terms of demographic variables such as gender, marital status, education, work experience and organizational position is presente

Table 1. The sample's demographic perspective.

\begin{tabular}{|c|c|c|c|}
\hline Demographic & Variable levels & Frequency & Frequency (\%') \\
\hline \multirow{3}{*}{ Gender } & Man & 118 & 84.9 \\
\cline { 2 - 4 } & Woman & 16 & 11.5 \\
\cline { 2 - 4 } & Missing data & 5 & 3.6 \\
\hline \multirow{4}{*}{ Marital status } & Married & 115 & 82.7 \\
\cline { 2 - 4 } & Single & 15 & 10.8 \\
\cline { 2 - 4 } & Missing data & 9 & 6.5 \\
\hline \multirow{4}{*}{ Education } & Diploma and lower & 13 & 9.4 \\
\cline { 2 - 4 } & The Diploma & 15 & 10.8 \\
\cline { 2 - 4 } & BA & 57 & 41 \\
\hline
\end{tabular}




\begin{tabular}{|c|c|c|c|}
\hline \multirow{4}{*}{ MA and Ph.D. } & 44 & 31.7 \\
\cline { 2 - 4 } & Professional Ph.D. & 5 & 3.6 \\
\hline \multirow{5}{*}{ Experience } & Missing data & 5 & 3.6 \\
\hline & Under 5 years & 28 & 20.1 \\
\cline { 2 - 4 } & 5 to 15 years & 68 & 48.9 \\
\cline { 2 - 4 } & 15 to 25 years & 12 & 8.6 \\
\cline { 2 - 4 } & Over 25 years total & 26 & 18.7 \\
\cline { 2 - 4 } & Missing data & 5 & 3.6 \\
\hline Organizational Post & Under 5 years & 28 & 20.1 \\
\cline { 2 - 4 } & 5 to 15 years & 68 & 48.9 \\
\cline { 2 - 4 } & 15 to 25 years & 12 & 8.6 \\
\cline { 2 - 4 } & Over 25 years total & 26 & 18.7 \\
\cline { 2 - 4 } & Missing data & 5 & 3.6 \\
\hline
\end{tabular}




\section{CONCEPTUAL MODEL FOR RESEARCH}

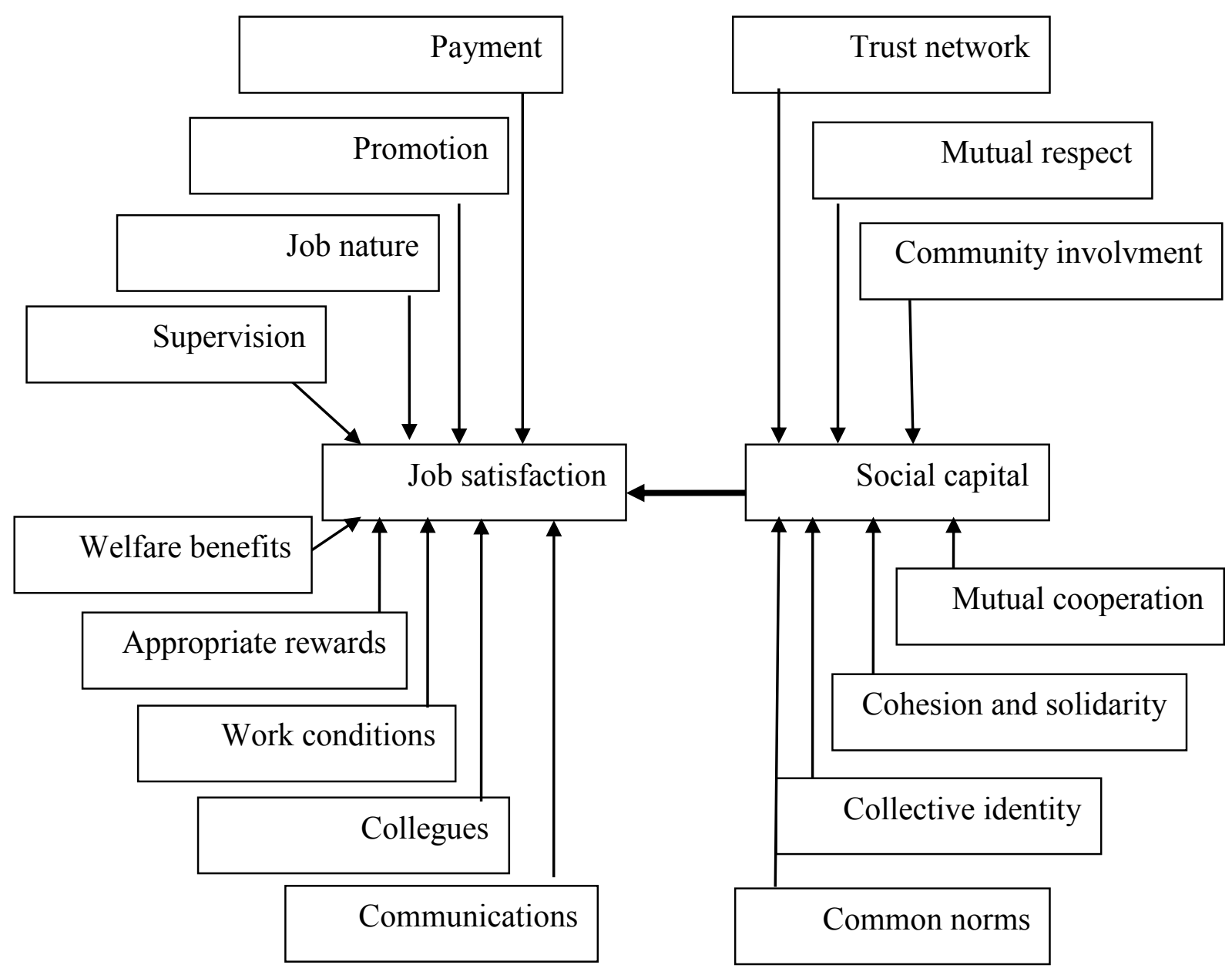

Figure 1. Conceptual Model for Research.

\section{2. Factor Analysis}

In current research, the accepted factor analysis was applied through LISREL software. The results of mentioned factor analysis were separately analyzed through LISREL software for each variable included. In order to reduce the variables and consider them as unobserved ones, the factor load should be more $0 / 3$. The key question is to find whether the measurement models are appropriate or not. To answer the mentioned question, X2 and other factors related to appropriateness of model should be thoroughly evaluated. The less K2 test, the better the research result because the mentioned test is mainly concerned on showing the difference between the data and the model. 


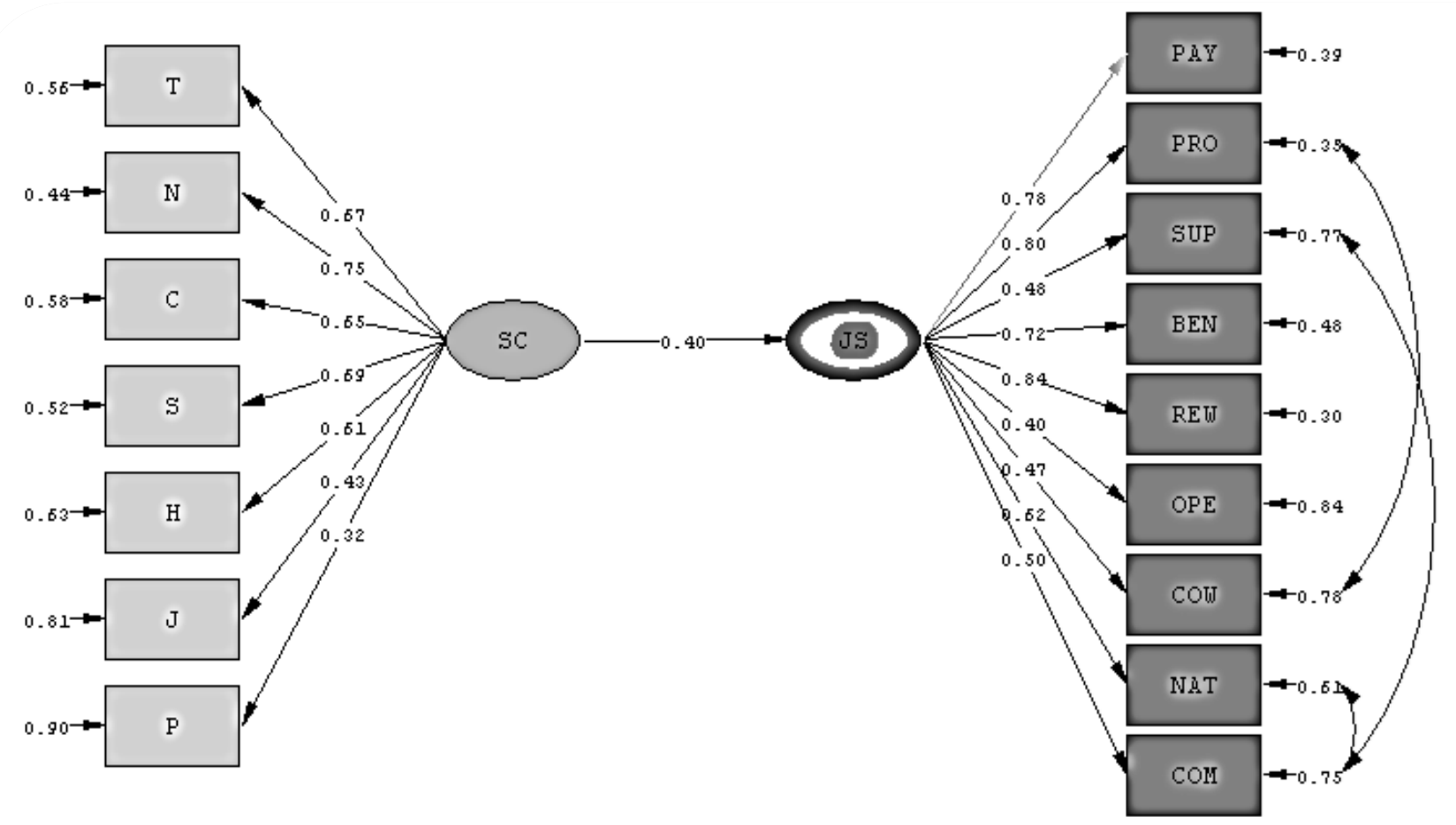

Chi-Square=199.82, df=99, P-value=0.00000, RMSEA=0.086

Diagram 1. Structural models to estimate the standard mode of research.

The difference rate between the observed data and conceptual model is low when the mentioned factor is low. The less RMSEA test, the better the result because this average is the square of model errors.

The acceptable RMSEA limit is 0.08 . Considering the fact the acceptable rate for Tvalue is higher than 1096 and lower than -1.96, all questions except for 58 and 61 had acceptable T-value in the first factor analysis of social asset. Then the mentioned questions were omitted.

In the second factor analysis, all aspects had acceptable T-value. In the first factor analysis, the job satisfaction T-value for all questions except for 2 and 31 were acceptable. In the second factor analysis, the job satisfaction for all questions and aspects were acceptable. 


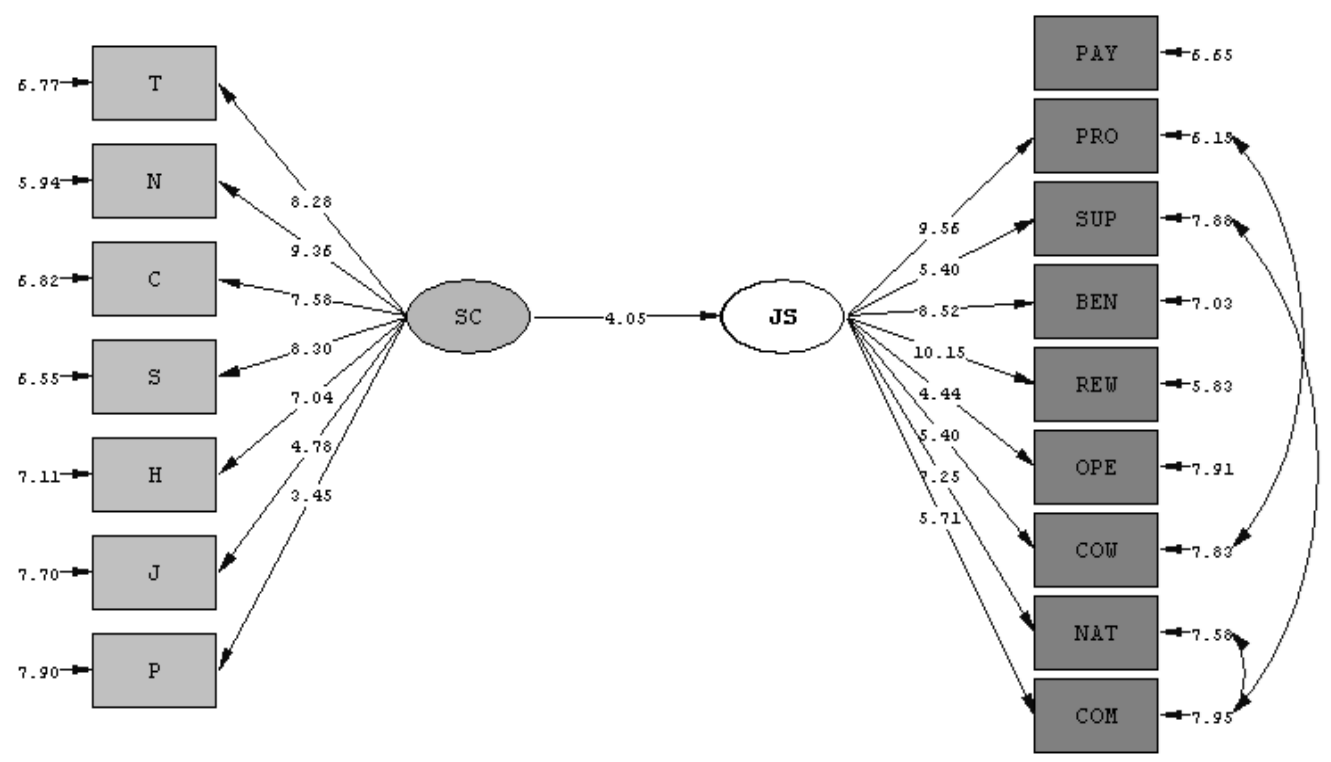

Chi-square=199.82, df=99, P-value=0.00000, RMSEA=0.086

Diagram 2. Structural models in significant numbers.

Table 2. The Comparison of measurement model.

\begin{tabular}{|c|c|c|c|c|c|}
\hline Measurement Model & $\begin{array}{c}\text { Confirmatory factor } \\
\text { analysis }\end{array}$ & $\mathrm{X}^{2}$ & $\begin{array}{c}\text { Degrees of } \\
\text { freedom }\end{array}$ & $\mathrm{X}^{2} / \mathrm{df}$ & RMSEA \\
\hline Social capital & First & 569.57 & 276 & 2.06 & 0.088 \\
\cline { 2 - 6 } & Second order & 649.74 & 290 & 2.24 & 0.085 \\
\hline Job Satisfaction & First & 1030.35 & 558 & 1.84 & 0.078 \\
\cline { 2 - 6 } & Second order & 78.21 & 29 & 2.69 & 0.081 \\
\hline \multirow{2}{*}{$\begin{array}{c}\text { Effect of social capital } \\
\text { on job satisfaction }\end{array}$} & & 199.82 & 99 & 2.01 & 0.086 \\
\hline
\end{tabular}


And in Structural model to investigate the amount of RMSEA is eual to 0.10 that after the necessary modifications, the amount of $\mathrm{X}^{2} / \mathrm{df}$, t-value and RMSEA is eual to 2.01, 4.05, 0.086 that suggest the suitable research structure model.

\section{CONCLUSION AND RECOMMENDATION FOR FUTURE RESEARCH}

The effects of these advantages on job satisfaction made us thoroughly follow the current research to find out better approaches for developing the efficiency of organizations. As mentioned earlier, there has been no definite framework to be applied for mentioned variables in Iranian organizations. Besides, most materials were introduced by different experts. The main achievements of current research are mainly concerned on deriving the researchers' minds to thoroughly study the social asset aspects and job satisfaction, making the random studies as most coherent and gathering the data as most efficient.In the first and second factor analysis, the social asset and job satisfaction were thoroughly studied and all the questions except for 58 and 61related to social asset and 2 and 31 ones related to job satisfaction had acceptable tVALUE. Then these questions were omitted. Finally the research structural model was evaluated. Considering the rates of X2/df, T-value and RMSEA as equal to 2.01, 4.05 and 0.086 in order, the appropriateness of the mentioned model is being verified. It can be concluded the social asset impacts on the job satisfaction. Besides, the employees' job satisfaction can be increased through increasing the social asset. Since the research findings and results may be limited due to the environments, the future researches may result in newer findings. Besides, the effect of two structural and recognition-based aspects of social asset on job satisfaction will be considered in future studies. Naturally, the researches on approaches related to increasing the social asset may lead to improved mentioned variables.

\section{References}

[1] Abbaszadegan, Mohammad (2003)"to manage the troubled organization" desert Publications, Tehran.

[2] Anneli Kasa, Technovation 29 (2009) 218-233.

[3] Chirwa M. L., Greeff M., Kohi T. W., Naidoo J. R., Makoae L. N., Dlamini P. S., Kaszubski C., Cuca Y. P., Holzemer W. L., Journal of the Association of nurses in Aids Care 20(1) (2009) 14-21.

[4] Chuang Y. C., Chuang K. Y., Social Science \& Medicine 67 (2008) 1321-1330.

[5] Faghihi Abolhassan, Feizi Tahere, Journal of Knowledge Management 19(72) (2007) 23-46.

[6] Fujisawa Y., Hamano T., Takegawa S., Social Science \& Medicine 69 (2009) 500-505.

[7] Gholipour Rahmatullah, Mdhvshy Mehrdad, Jafarian Vahid (2009), "analyzed the impact of social capital on corporate entrepreneurship (Case Study Sadid Industrial Group)" managerial culture Qom Tehran University campus, the sixth year of the Seventh

[8] Goyal A., Akhilesh K. B., Team Performance Management 3(1/8) (2007) 206-226.

[9] Haji Karimi, Abbas Ali, Faraji Marjan, Journal of Public Management, School of Management 1(1) (2009) 51. 
[10] Homan Haider Ali (2003). "Prepared by the standard measures of job satisfaction," first published in Tehran, the State Management Training Center .

[11] Mirsepasi Naser (2009). "Strategic management of human resources and labor relations: the attitude to globalization," Third Edition, Tehran, Mir Publishing.

[12] Mohammadi Hamed (2010) "new public management and the need for the cooperatives" Cooperative, in the twentieth, No. 207-206.

[13] Moshabaki Asghar, Ghlichli Behroz, (2008) "Competitive Advantage: decisive role of intellectual capital and social capital (the case of two Iranian car company)" Teacher of Humanities, Faculty of Humanities (Management), Volume XI, No. III, 55 consecutive

[14] O'Leary P., Wharton N., Quinlan T., International Journal of Health Care Quality Assurance 22(3) (2009) 221-231.

[15] Oorschot W., V. Finsveen, International Journal of Sociology and Social Policy 30(3/4) (2010) 182-193.

[16] P. Robbins Stephen (1999). "Organizational Behavior, Concepts, Theory and Applications", A. Parsian, Mohammad Arab, second edition, twelfth printing, Tehran's Cultural Research Bureau.

[17] Pare' Sylvie, Menzies Teresa V., Journal of Enterprising Communities: People and Places in the Global Economy 2(1) (2008) 52-72.

[18] Paul J. Ferri, David Deakins, Geoff Whittam, Journal of Enterprising Communities: People and Places in the Global Economy 3(2) (2009) 138-151.

[19] Rebbeca N. Hutchinson, Mary A. Putt, Lorraine T. Dean, Judith A. Long, Chantal A. Montagnet, Katrina Armstrong, Social Science \& Medicine 68 (2009) 1859-1865.

[20] Robert Oxoby, Journal of Social Economics 36(12) (2009) 1133-1152.

[21] Smith Janel, The Learning Organization 16(6) (2009) 460-468.

[22] Suzuki E., Takao S., Subramanian S. V., Komatsu H., Doi H., Kawachi I., Social Science \& Medicine 70 (2010) 1367-1372.

[23] Veisi G. H.; literacy, Muhammad Ali (2007)"Rftarsazmany look at the management" of the Islamic Research Institute (Iranian Revolutionary Guards of Islamic revolution represented supreme leader] Qom, Zamzam guidance

[24] Yazdanpanah L., Samadian Fatima, May, Persian date Khordad (2010). "Factors affecting the success of cooperative companies handicrafts Kerman case study" of cooperation, in the twentieth, No. 203-202,

[25] Zarei Matin H., (2010). "Management of Organizational Behavior" Advanced Printing, Tehran, specific orientation. 